\title{
Public financing of cooperative $R \& D$ projects in Spain: the Concerted Projects under the National R\&D Plan
}

\author{
Juan Acosta Ballesteros ${ }^{\mathrm{a}, *}$, Aurelia Modrego Rico ${ }^{\mathrm{b}}$ \\ ${ }^{a}$ Departamento de Análisis Económico, Universidad de La Laguna, Campus de Guajara 38201 La Laguna, Santa Cruz de Tenerife, Spain \\ ${ }^{\mathrm{b}}$ Instituto Flores de Lemus, Universidad Carlos III de Madrid, Madrid, Spain
}

\begin{abstract}
This work will analyse the factors which influence decision-making within the Spanish public sector on the financing of precompetitive research projects developed by firms in collaboration with universities and public research organisms. With this objective in mind, an econometric model is proposed that explains simultaneously the concession of aid on behalf of the public sector and the amount of such aid. The estimates carried out indicate, among other results, that the destination of the budgeted funds explains a large part of the public financing received. However, all the evidence would seem to indicate that the funding has not been awarded either in order to significantly favour those firms which most need it, nor to give incentive to high levels of cooperation.
\end{abstract}

Keywords: Public financing of R\&D projects; Cooperation between public research centers and firm; Science and technology policies; Models with self-selection

\section{Introduction}

The collaboration in $R \& D$ activities between firms and public research centres (PRCs) constitutes a strategic element towards innovation in the productive sector and towards the achievement of a better planning and exploitation of the resources set aside for research in the public sector. In this sense it is not surprising that there is a wide range of literature which analyses the factors and difficulties which determine the cooperation in $\mathrm{R} \& \mathrm{D}$ between private

\footnotetext{
* Corresponding author

E-mail address: jacosta@ull es (J Acosta Ballesteros)
}

and public sector. ${ }^{1}$ In parallel, governments of different countries place special interest in the design of adequate aid which expedites and promotes this type of collaboration.

In this work an instrument of technological policy existent in Spain, known as the Concerted Projects under the National R\&D Plan, will be analysed.

\footnotetext{
${ }^{1}$ The study of the ways in which relationships between the two collectives materialise has been covered in various works (Gibbons and Johnston, 1974; Link and Rees, 1990; Bailetti and Callahan, 1992; Senker and Faulkner, 1992; Bonacorsi and Piccaluga, 1994; Faulkner and Senker, 1994; Ham and Mowery, 1998) In others, the barriers which can make the establishment of relations between the two worlds difficult have been studied (Dean, 1981; Azároff, 1982; Fowler 1984; Höglund and Persson, 1987; Van Dierdonk et al , 1990; Sheen, 1992; Lee, 1996)
} 
This is a national initiative put into practice in 1988 that pursues two types of objectives: to foment R \& D activities in firm and to encourage cooperation between the latter and public research centres. The aid consists of the concession of interest-free loans to precompetitive research projects developed by businesses which, in most cases, must include the participation of a research team from universities and/or public research organisms.

These projects have been the object of various studies which have covered different aspects of interest. $^{2}$ However, none has analysed jointly the decisions on the part of the firm and of the administration involved in the financing of a concerted project (cooperative project), and the study of the determinants of the amount to be received.

The objective of this work is to identify and to analyse the factors which determine the financing approved for each project. The method used consists of the estimation of an econometric model with self-selection which explains the amount of the loan approved according to the characteristics of the firm, the project and the role of the organism managing the aid.

The first aspect to be examined in depth will be to what extent the financing received is related to the project budget and whether the intensity with which the projects are funded varies according to the destination of the allocated budget: acquisition of equipment, remuneration of researchers, etc.; or according to the place where funds are spent: firm or PRCs. The work also seeks to establish the degree of incidence which other characteristics of the project, such as its length or the thematic area (National Programme) in which it is registered, have in the financing received and, above all, whether the attributes of the firm affect the size of the loan significantly. Another element which must be included is whether the public action has tended to favour the integration into the system of science and technology, since this is one of the objectives of the Concerted Projects.

This paper is part of a broader research project on public action in the Concerted Projects in several

\footnotetext{
${ }^{2}$ Fontela et al ,1992; González Ayuso et al ,1993; Modrego, 1995; Molero and Buesa, 1997; Acosta and Modrego, 1997, 1998
}

fields. One line of research in which work is being carried out is the study of the effects of public funding of R\&D on performance. According to the article of Arora et al. (1998) the aim of this research is to determine whether or not those firms which have received aid have obtained better research results than the rest (for example, more patents or more indirect results such as higher sales or an increase in staff numbers in the firm) and whether the way in which the aid has been shared out has allowed these results to be as wide-reaching as possible.

The paper will be arranged as follows. A view of Spanish science and technology policy is offered and the figures which are most relevant to the concerted projects are presented in Section 2. In Section 3, an econometric model is formulated to explain the financing given to concerted projects. In Section 4 the variables used are described and, in Section 5, different specifications of the model will be presented in an attempt to answer the questions raised earlier. Lastly, concluding remarks on the implications for the design of science and technology policy will be offered.

\section{Spanish science and technology policy: con- certed projects}

The two main lines of action of Spanish science and technology policy are the National Plan for Scientific Research and Technological Development (National R\&D Plan) and the actions by the Ministry of Industry and Energy (MINER). In addition to these are international actions (joint programmes with European or Latin American countries, etc.), regional ones from the different autonomous communities and even some of those established by the central administration itself, such as for example the tax shield on R\&D activities undertaken by firms.

The National R\&D Plan was adopted in 1988 and, since then, sets the priorities for action, programmes the resources available and integrates action in the field of $\mathrm{R} \& \mathrm{D}$ of the productive sectors, research organisms and universities. The economic efforts of the National Plan are materialised in the provision of the National R\&D Fund. They are aimed largely at the fomentation of basic scientific 
research in universities and public research organisms. However, among the National Plan's objectives is the promotion of communication and concerted action between universities and public research organisms and firms. To this end, various mechanisms are put into place under the Plan, such as the following.

- The network of research results transfer offices (OTRI network), is made up of small units (OTRI) situated in universities, public research organisms, and business research associations. Their function is to promote the transfer of the scientific-technical offer of universities and public research organisms towards the productive sectors.

- The OTRI network uses the Programme of Stimulation of the Transfer of Research Results (PETRI) to incentivate basic and applied research groups to devote a part of their efforts to $R \& D$ activities the results of which can be transferred to firms. The PETRI actions serve to support the first stage of transfer of technology from PRCs to firms.

- The Concerted Projects, the Integrated Projects and the Cooperative Projects are also oriented towards the improvement of the articulation of the science and technology system. The first two attempt to foment collaboration by firms and PRCs in precompetitive research projects. The difference between the two instruments originates from the fact that the Integrated Projects support the undertaking of largescale projects which integrate diverse technologies. On the other hand, the Cooperative Projects fund collaboration between firms and technological centres.

While the actions of the National R\&D Plan are oriented towards basic research and the precompetitive development of technology, Spanish technological policy can be included under the actions carried out by the MINER with a view to favouring industrial innovation. The intervention is designed, among other things, to give incentive to the efforts in technological development and the incorporation of advanced technologies in firms and to improve the competitivity of Spanish industry through an improvement in the quality of its products.

Together with the actions managed by the MINER itself, there is also technological promotion work carried out directly by the Centre for Technological Industrial Development (CDTI). The CDTI is depen- dent on the MINER, and ones of its tasks is the funding out of its own budget of research and development projects carried out by firms. Worth noting are the Technological Development Projects which consist of the awarding of loans at privileged interest rates for projects which are close to the market, generally coordinated with the bridge programmes put into place by the MINER.

Furthermore, the CDTI manages programmes which have been delegated to it by other institutions, the clearest example being the concerted projects. ${ }^{3}$ The management by the CDTI of funds of a strongly business nature is justified not only by an attempt for there to be coordination between organisms but also by the CDTI's capacity to assess the technological and economic-financial content of the development projects in which firms participate.

The CDTI is also charged with other tasks such as the industrial exploitation of the technologies developed by firms, the promotion of collaboration between industries and research centres or the management of Spanish firms' participation in international R \& D programmes.

After this overview of Spanish scientific and technological policy it should be clear that the concerted projects are the fundamental instrument with which precompetitive research in firms is supported. Furthermore, their management being the CDTI's responsibility, coordination is guaranteed with the MINER instruments, which can be applied simultaneously.

Having situated the concerted projects in the context of Spanish scientific and technological policy as a whole, it is worth paying some attention to the evolution of this instrument during the period over which public funding is analysed (1988-1991).

Table 1 shows the annual budgets of the National R\&D Fund and the total amount of the commitments made by the National R\&D Plan for concerted projects in monetary terms and in relation to the total amount of public funds. While the National R \& D Fund budget shows a certain amount of stabil-

\footnotetext{
${ }^{3}$ This work on the part of the CDTI is not new, since it already collaborated in the research projects which requested public aid through the mechanism of what were known as the Concerted Plans, predecessors of the Concerted Projects
} 
Investment and funding in the concerted projects in the period 1988-1991

\begin{tabular}{|c|c|c|c|c|}
\hline & 1988 & 1989 & 1990 & 1991 \\
\hline National R\&D Fund budget & 13,043 & 19,703 & 24,224 & 19,919 \\
\hline Plan's commitments with concerted projects & 4785 & 5758 & 6558 & 5805 \\
\hline Commitments with concerted projects / National R\&D Fund & $366 \%$ & $292 \%$ & $270 \%$ & $291 \%$ \\
\hline Number of projects & 76 & 124 & 129 & 114 \\
\hline Total investment budget & 9465 & 12,666 & 15,471 & 14,016 \\
\hline Investment commitments National Plan & 4785 & 5758 & 6558 & 5806 \\
\hline Percentage of investment by National Plan in total budget & 51 & 46 & 42 & 41 \\
\hline Public subsidies & 1161 & 1703 & 2499 & 2433 \\
\hline Percentage of public subsidies in the total budget & 122 & 134 & 161 & 173 \\
\hline
\end{tabular}

Monetary figures are expressed in millions of Pesetas

Source: Arnés (1990) and Memoria de actividades del Plan Nacional de I + D 1991 (National R\&D Plan Report 1991) Own elaboration

ity throughout the period, with figures of around 20,000 million pesetas, in 1991 the amount devoted to concerted projects is reduced.

Table 1 develops the previous idea further, showing that since 1988 the number of projects approved increases, as do both the total amount provided by the National R\&D Fund and the total budget of the projects, reaching a figure of 15,000 million pesetas in 1990. However, in 1991 all three indicators decreased. The average percentage of investment financed through interest-free loans was reduced from the 1988 figure of $51 \%$ to $41 \%$ in 1991 .

However, it is necessary to point out that public support for concerted projects is not confined to interest-free loans but also covers public subsidies from various sources such as the MINER or the autonomous communities. Table 1 shows that in the period 1988-1991 the proportion of subsidies increased by more than five percentage points.

\section{The model}

The financing granted to each concerted project $(F)$ depends on a vector of characteristics of the project $\left(z_{F}\right)$, on variables relative to the firm which carries it out $\left(x_{F}\right)$ and on others which reflect the behaviour of the organism which manages the aid $\left(w_{F}\right)$. This relation, which is established in Eq. (1), is assumed to be lineal and incorporate a random perturbance $\left(u_{F}\right)$ which is normally distributed.

$F=x_{F} \beta_{F}+z_{F} \gamma_{F}+w_{F} \theta_{F}+u_{F}$
The estimation of this equation, however, comes up against the problem that the financing is not directed to randomly chosen $R \& D$ projects, but to those projects which have been presented and approved as concerted projects. As a consequence, the estimation of Eq. (1) by itself, without taking into account the effect of this selection process, gives rise to inconsistent estimations if the financing granted is not independent of the selection process of the projects or, to put it another way, if unobserved factors exist which influence both the probability that a concerted project may be approved and the quantity of the loan granted.

The solution to this problem lies in proposing and estimating models with self-selection, in which, together with the rule of financing, the mechanism through which the selection of projects ${ }^{4}$ is incorporated, introducing in an explicit way the behaviour of the firms and the public agency. There are two decisions to be considered: firstly, firms must decide whether or not to apply for a loan for a particular $\mathrm{R} \& \mathrm{D}$ project and, later, the administration decides which projects are to receive financing and how much the interest-free loan granted to them will be.

The estimation of a model such as the one described raises serious difficulties since it requires

\footnotetext{
${ }^{4}$ For a description of the problematic and methods of estimation of the models with autoselection, Maddala (1983, 1986), Amemiya (1984), Dhrymes (1986) and Greene (1991) can be consulted Manski and Wise (1983) and Busom (1991) have also served as a reference for the formulation of the model
} 
having available information on the research projects for which this type of financing was not sought, whether or not they were finally developed by the firms. Also, as the administration maintains the anonymity of the companies which present proposals that are rejected, the information available does not allow the differentiation between firms which have applied for concerted projects and have not been successful in their application and those which have not made any such application. The solution which has been adopted consists of rearranging the decisions of the two agents into a single latent variable $\left(I^{*}\right)$ which includes the propensity of a firm to have a concerted project and which depends only on the attributes of the firm $\left(x_{I}\right)$. In this way the selection mechanism is reduced to an equation of participation according to which some firms present an application for financing and obtain it, whilst others present no such application, or apply but are rejected. ${ }^{5}$

In short, the model to be estimated is given by Eq. (2), in which it has been assumed that the perturbations $u_{I}$ and $u_{F}$ are distributed jointly as a bivariant normal, with covariance $\rho \sigma_{F}$ If both terms of error were not correlated ( $\left.\rho \sigma_{F}=0\right)$ self-selection would not exist and therefore it would be unnecessary to estimate the participation and financing equations jointly.

$$
\begin{aligned}
& I^{*}=x_{I} \beta_{I}+u_{I} \\
& I=1 \text { if } I^{*}>0 \quad \text { (participation) } \\
& I=0 \text { if } I^{*} \leq 0 \quad \text { (non-participation) } \\
& F=x_{F} \beta_{F}+z_{F} \gamma_{F}+w_{F} \theta_{F}+u_{F} \quad \text { if } I=1
\end{aligned}
$$

$F$ is not observed if $I=0$

\footnotetext{
To dispense with the effect of the characteristics of the projects on the selection process appears to be acceptable if it is taken into account that the model will be estimated using the four years which constitute the first phase of the National Plan for R\&D In this way, a firm which has not made use of a concerted project has had more than one opportunity to present project, should it have wanted to If a proposal had been rejected on the grounds of being technically or financially unviable, the firm would have been able to improve the proposal, or replace it with another in later applications, adapting it to the minimum requirements Consequently, of in the total period the firm has not developed any concerted project, it is quite possibly due the fact that the characteristics of the firm or of its research as a whole do not make it possible or desirable to do so
}

Model (2) presents the disadvantage that it does not specify separately the decisions to request a concerted project and to award it. Consequently, it does not make it possible to analyse the application process and the concession of aid. However, it is adequate to avoid the self-selectivity problem. In this way, consistent estimations are obtained of the parameters of the financing equation.

\section{Explanatory variables}

To carry out this work a database with 1099 observations was built up, of which 722 correspond to firms which are developing $\mathrm{R} \& \mathrm{D}$ activities in Spain at the end of the 1980s and the beginning of the 1990s, but which have not received aid through a concerted project between 1988 and 1991, and the remaining 377 refer to concerted projects carried out by another 255 firms. ${ }^{6}$ The funding awarded to the 377 concerted projects which constitute the unit of analysis is estimated according to model (2). The participation equation uses the characteristics of the 722 firms which are not awarded a concerted project and the 255 which carry out the 377 projects considered. The data comes from the CDTI and the Interministerial Commission for Science and Technology (CICYT).

The variables used in the estimation of model (2) are divided into three groups, which, in accordance with the above exposition, correspond to the vectors $x, z$, and $w$.

\subsection{Variables relating to the firm}

For the estimation of the model, five variables (indicators) which synthesize the main characteristics of the firm have been used, as seen in Table 2. These variables have been obtained in a previous paper (Acosta and Modrego, 1997) in which the information available about the firms has been related to

\footnotetext{
${ }^{6}$ Although 443 concerted projects were approved in the period 1988-1991, the information on some of them was not sufficiently good and it was therefore decided to dispense with these observations, which do not seem to have common characteristics
} 
ORRD Reflects the degree to which the firm is orientated towards research activities and technological development

RDCA Summarises the research capability of the firm, especially that which is related to the size of the R\&D department

OTHER Other motives for participation in the concerted projects

PROXI Reflects the fact that some firms need more public support to carry out research tasks or, at least, they are more interested in it

their participation in the concerted projects. The indicators are the coordinates of the firms in the axis obtained through an analysis of multiple correspondences $^{7}$ and they adequately summarise the inertia of the cloud of firms, especially in relation to the realisation of concerted projects.

The information available included, among other, sales, staff, personnel dedicated to research, spending on $R \& D$ activities by the firm, intensity with which the firm dedicates its human resources and materials to research tasks, autonomous community in which the firm is situated, age, field of activity and, of course, information about whether the firm has been awarded any concerted project between 1988 and 1991.

To summarise the interpretation of the five indicators, the following may be said: The first one (SIZE) is the first factor of the multiple correspondence analysis, and reflects the size of the firm, since $44.5 \%$ of its inertia comes from the sales and staff variables. The situation of other variables - such as $R \& D$ personnel or $R \& D$ spending, which are also influenced by the size of the firm, reinforce this interpretation.

The analysis of the second factor shows that it counterpoises firms whose dedication to research tasks is small with firms oriented towards these activities, both in absolute terms ( $\& \& D$ spending and $R \& D$ personnel) and in relative terms $(R \& D$

\footnotetext{
${ }^{7}$ Most of the variables contained in the original databases are continuous However, they have been grouped into intervals, obtaining discrete variables, since this transformation makes the information easier to understand and allows the inclusion of variable qualitative analyses
}

spending in relation to sales and $\mathrm{R} \& \mathrm{D}$ personnel in relation to the total number of staff). For this reason, this factor (ORRD) can be related to the vocation to carry out $\mathrm{R} \& \mathrm{D}$ activities.

The third indicator (RDCA) synthesises the firm's research capacity in terms of the size of its $R \& D$ department. It explains above all that firms with small R\&D departments do not tend to carry out concerted projects. Thus, if the second factor indicates that firms which put a great emphasis on $R \& D$ activities are more likely to undertake concerted projects, the third indicator shows that there are small firms which, although they devote a significant part of their resources to $\mathrm{R} \& \mathrm{D}$, do not reach the minimum scale necessary to undertake concerted projects.

Factors four and five cover peculiarities which are not included in the three previous indicators. Despite the fact that the synthesised inertia for these factors is low, they are used in the estimation of the model since they help discriminate those firms with a concerted project. The fifth (PROXI) has been interpreted as interest (or need) for public aid. It shows that small firms with small R\&D departments tend to carry out more CDTI-managed projects than would seem to be in accordance with the first three factors, while those which have more resources have less of a tendency to establish relations with the CDTI. Finally, it has not been possible to find a clear significance for the fourth factor (OTHER), however, firms with concerted projects tend to have positive coordinates. For this reason, it has been attributed to mean other motives for participation in the Concerted Projects.

As well as the factors, a dummy variable is introduced for each of the seven sectors of activity that appear in Table 3, in which the firms have been 
Table 3

Sectors of activity

C1 Agriculture, stockbreeding and fishing

C2 Energy and water

C3 Extraction and transformation of non-energetic minerals Chemical industry

C4 Other manufacturing industries

C5 Construction

C6 Rest of sectors

C7 Financial institutions, insurance and services

classified according to the first digit of the National Classification of Economic Activities (CNAE). ${ }^{8}$

\subsection{Variables relating to the project}

The variables which describe each project (Table 4) refer both to its total budget and to the destination of the latter, and also take into account the length of the project measured in months (variable DU). The budget is broken down into acquisition of equipment, materials and other expenses both by the firm and by the PRCs which might participate in the project. It also included spending on staff.

Since one of the objectives of the concerted projects is to encourage collaboration between firm and PRCs, it is interesting to find out whether the public financing has been directed specially towards those projects with greatest collaboration with PRCs. In order to include this effect in the model, the results of a work in which the characteristics of the concerted projects for the period 1988-1991 are analysed (Acosta and Modrego, 1998) have been taken into account. In this document it is shown that the participation of the firm in the project depends more on the degree to which it is involved in R\&D tasks than the relation between the size of its $\mathrm{R} \& \mathrm{D}$ de-

\footnotetext{
${ }^{8}$ It is worthy of note that the immense majority of firms of branch 8 of the CNAE (variable $\mathrm{C} 7$ ) provide services to other firm (CNAE code 84) Within the metal transformation industry (C3) those belonging to the chemical industry (25) stand out as do, in a lesser way, those belonging to the non-metallic mineral product industry (24) As detected by González Ayuso et al (1993), in the category of the rest of sectors (C6) there is a significant number of firms in the wholesale trade sector (61), which really include subsidiaries of large companies from the information technology or automobile sectors
}

partment and the size of the project. That is to say, the evidence seems to indicate that the collaboration with PRCs is more orientated towards completing a research task of the firm than towards relieving the R \& D department of workload. This result is in accordance with the works which have detected that the possibilities which a firm has to benefit from outside contributions depend on its own research capability (Mowery, 1983; Arora and Gambardella, 1991; Mowery and Rosenberg, 1989; Cohen and Levinthal, 1989, 1994; Veugelers, 1997).

The consequence of this conclusion is that in order to explain the participation of public researchers in concerted projects, it is necessary to analyse in detail the capabilities of the firms and the PRCs, as well as the attitudes of both agents to the joint realisation of $\mathrm{R} \& \mathrm{D}$ activities. Although there are no sufficient variables to analyse in detail the causes of collaboration, an indicator - COLAB variable — obtained by Acosta and Modrego (1998) is available and reflects the degree to which the PRCs involve themselves in a concerted project ${ }^{9}$ or, alternatively, the sharing out of research tasks between the firm and the universities and PRCs. In any case, this indicator not only measures the importance of the PRCs' collaboration, but also reflects the existence of a relation between the degree to which the firm is truly dedicated to R\&D tasks (measured by the percentage of spending on $R \& D$ over sales and the proportion of staff devoted to R\&D) and the intervention of the researchers from the public sector in the project.

\subsection{Variables relating to the public performance}

Dummy variables referring to the year in which the concerted project was approved have been introduced; thus the variables CON1, CON2, and CON3 refer, respectively, to the differential effect in relation to 1991 of the 1988,1989 or 1990 invitations for applications. Together with these, other aid

\footnotetext{
${ }^{9}$ It is related in a significant way with the distribution of the project budget and the spending on personnel between the firm and the PRC It also includes the number of researchers supplied by the firm and the PRC for the project
} 
Table 4

Components of the project budget ${ }^{\mathrm{a}}$

\begin{tabular}{ll}
\hline BUDGET & Total project budget \\
BILAB & Investment in laboratory equipment for the firm \\
BIFA & Investment in other fixed assets for the firm \\
BLABO & Spending on labour in the firm \\
BMATE & Spending on materials carried out by the firm \\
BOTHER & Other spending carried out by the firm \\
BNOTI & Budget dedicated by the firm other than to the investment: BLABO + BMATE + BOTHER \\
CEQUI & Investment in equipment for the public research centres (PRCs) \\
CLABO & Spending on labour by PRCs \\
CMATE & Spending on materials carried out by PRCs \\
COTHER & Other spending carried out by PRCs \\
CNOTI & Budget carried out by PRCs other than to the investment in equipment: CLABO + CMATE + COTHER \\
CTOTAL & Cost of collaboration of PRC: CEQUI + CNOTI \\
NOINV & Budget dedicated other than to investment: BNOTI + CNOTI
\end{tabular}

${ }^{\mathrm{a}}$ All variables are measured in millions of Pesetas

granted by the public sector to the same project has been considered, OTRPUB being the sum of all these.

Finally, a dummy variable has been included for each of the 15 thematic areas or National Programmes in which the project can be inserted ${ }^{10}$, as shown in Table 5. These variables not only reflect the variability in the public performance according to the technological objectives of the concerted projects, but also characterise the projects, since they reflect the differences between technologies.

\section{Results of the estimation}

The estimation of the parameters of model (2) has been obtained by jointly applying the method of maximum likelihood. Tables 5 and 6 show the results of the estimation of the model for the three specifications, which have the same independent variables in the participation equation, but which are differentiated by the variables included in the financing equation.

\footnotetext{
${ }^{10}$ The prioritisation of the research funded by the National Plan has been specified in National Programmes up to 1999 From 2000 onwards it will be based on technological areas and sectors of activity
}

\subsection{Participation equation}

Table 6 shows the results of the estimation of the model including as regressors the variables relating to the firm and the dummy variables which indicate that each of the firms belongs to a specific sector of activity (variables $\mathrm{C} 1$ to $\mathrm{C} 7$ ). All of these variables are significant both individually and as a whole and the predictive capacity of the participation equation is high, since around $78 \%$ of the observations are adequately classified by the model.

The indicator of the size of the firm (SIZE) is not significant and has therefore been eliminated from

Table 5

National Programmes

\begin{tabular}{ll}
\hline ROB & Advanced automatization and robotics \\
BIO & Biotechnology \\
AGR & Agricultural research \\
FAR & Pharmaceutical research and development \\
GAN & Stockbreeding research and development \\
ESP & Space research \\
MIC & Microelectronics \\
MAT & New materials \\
NAT & Conservation of natural patrimony and processes of \\
& environmental degradation \\
GEO & Geological resources \\
MAR & Marine resources and aquiculture \\
SAL & Health \\
POR & Forest systems and resources \\
ALI & R\&D in food technology \\
TIC & Information technology and communications \\
\hline
\end{tabular}


Participation equation

\begin{tabular}{|c|c|c|c|c|c|c|}
\hline \multirow[t]{2}{*}{ Variable } & \multicolumn{2}{|c|}{ Specification 1} & \multicolumn{2}{|c|}{ Specification 2} & \multicolumn{2}{|c|}{ Specification 3} \\
\hline & Parameter & $t$-Student ${ }^{\mathrm{a}}$ & Parameter & $t$-Student ${ }^{\mathrm{a}}$ & Parameter & $t$-Student ${ }^{\mathrm{a}}$ \\
\hline ORRD & 13034 & 1141 & 12997 & 1153 & 12972 & 1157 \\
\hline RDCA & 11127 & 759 & 11138 & 774 & 11112 & 775 \\
\hline OTHER & 08406 & 641 & 08438 & 645 & 08441 & 647 \\
\hline PROXI & 14528 & 870 & 14464 & 876 & 14492 & 884 \\
\hline $\mathrm{C} 1$ & -09956 & -328 & -09947 & -330 & -09944 & -330 \\
\hline $\mathrm{C} 2$ & -07963 & -343 & -07741 & -343 & -07658 & -341 \\
\hline $\mathrm{C} 3$ & -07150 & -692 & -07078 & -700 & -07092 & -701 \\
\hline $\mathrm{C} 4$ & -09232 & -1163 & -09329 & -1186 & -09306 & -1185 \\
\hline C5 & -04221 & -320 & -04208 & -326 & -04274 & -331 \\
\hline C6 & -11272 & -599 & -11236 & -597 & -11246 & -599 \\
\hline C7 & -09341 & -544 & -09175 & -560 & -09142 & -563 \\
\hline
\end{tabular}

${ }^{\mathrm{a}}$ The statistics $t$ of Student are robust to the presence of heterocedasticity (White, 1980)

the definitive specifications. This is an important result in that it allows the affirmation that the size of the firm has not had incidence in the participation in the concerted project programme, although indirectly other characteristics which could in part be related to the size, such as research capability, have had incidence.

The parameters which accompany the variables ORRD, RDCA and OTHER indicate that the firms which are most intensely involved in $\mathrm{R} \& \mathrm{D}$ activities and with most capacity to carry them out are the ones most prone to making use of a concerted project. Also, the need or interest for public support, measured by the variable PROXI, affect the probabil ity of embarking upon this type of research project.

In any case, it should not be forgotten that this equation serves to correct the selection bias, which could affect the parameters of the financing equation, and not to analyse in detail the reasons behind firms' participation.

\subsection{Financing equation}

The financing awarded has been made to depend upon the breakdown of costs of the project, its duration and the financing provided by other organisms of the central or autonomous administration. It is also considered relevant the introduction of dummy variables reflecting the effect on financing of each of the four call of proposals for concerted projects, although in practice the first one (1988) is the only significant one because the financing granted was exceptionally high.

Moreover, after proposing multiple alternatives and carrying out contrasts of hypotheses, it was decided to include the variable which measures the PRC collaboration (COLAB), the variables which characterise the firms and the dummy variables of the National Programme, leaving out those from the activity sector. ${ }^{11}$ In the various estimated specifications, the indicator which reflects the size of the firm (SIZE) does not have a significant effect on the financing, and was therefore eliminated leaving as regressors only the other four factors.

In specification 1 of Table 7 , it can be observed that the contribution of the National Plan, compared with other sources of spending, is smaller when the funds of the project are destined for the acquisition of fixed assets for the firm, especially if they are not strictly related to the research activity. That is to say, the tendency is, logically, to finance the costs which are most directly related to the project, especially if they are specific to the latter and do not extend to other research being carried out by the firm. The above result contrasts with the fact that the equipment costs destined to PRCs are completely financed (it is not possible to reject the hypothesis that the

\footnotetext{
${ }^{11}$ In fact, it is more reasonable to introduce the variables of the National Plan because they are an attribute of the project which is being financed, while the sector of activity characterises the firm
} 
Table 7

Financing equation

\begin{tabular}{|c|c|c|c|c|c|c|}
\hline \multirow[t]{2}{*}{ Variable } & \multicolumn{2}{|c|}{ Specification 1} & \multicolumn{2}{|c|}{ Specification 2} & \multicolumn{2}{|c|}{ Specification 3} \\
\hline & Parameter & $t$-Student ${ }^{\mathrm{a}}$ & Parameter & $t$-Student ${ }^{\mathrm{a}}$ & Parameter & $t$-Student ${ }^{\mathrm{a}}$ \\
\hline BILAB & 03996 & 4148 & 03987 & 4961 & 03998 & 5014 \\
\hline BIFA & 03022 & 1056 & 03001 & 1093 & 03006 & 1120 \\
\hline CEQUI & 10617 & 1003 & 10662 & 943 & 10818 & 1015 \\
\hline BLABO & 04708 & 2424 & & & & \\
\hline BMATE & 04425 & 1282 & & & & \\
\hline BOTHER & 04668 & 2546 & & & & \\
\hline BNOTI & & & 04630 & 4059 & & \\
\hline CLABO & 04510 & 1125 & & & & \\
\hline CMATE & 06093 & 747 & & & & \\
\hline COTHER & 04856 & 767 & & & & \\
\hline CNOTI & & & 04824 & 1667 & & \\
\hline NOINV & & & & & 04658 & 4256 \\
\hline DU & 0157 & 301 & 0159 & 323 & 0160 & 325 \\
\hline CON1 & 8690 & 589 & 8594 & 587 & 8559 & 583 \\
\hline OTRPUB & -03386 & -1313 & -03344 & -1390 & -03331 & -1398 \\
\hline ORRD & -9747 & -556 & -9823 & -594 & -9861 & -595 \\
\hline RDCA & -8111 & -395 & -8443 & -453 & -8384 & -452 \\
\hline OTHER & -7721 & -393 & -7637 & -390 & -7746 & -416 \\
\hline PROXI & -11071 & -464 & -11187 & -470 & -11312 & -500 \\
\hline COLAB & -2036 & -179 & -2119 & -194 & -1825 & -229 \\
\hline ROB & 1682 & 075 & 1026 & 050 & 1236 & 061 \\
\hline $\mathrm{BIO}$ & -6025 & -194 & -5591 & -171 & -5599 & -176 \\
\hline AGR & -4411 & -109 & -4814 & -118 & -4646 & -114 \\
\hline FAR & -7876 & -316 & -6708 & -321 & -6580 & -316 \\
\hline GAN & -3595 & -062 & -2981 & -046 & -2691 & -043 \\
\hline ESP & 3570 & 157 & 3814 & 180 & 3964 & 186 \\
\hline MIC & 7511 & 231 & 7362 & 227 & 7372 & 226 \\
\hline NAT & -1072 & -026 & -1133 & -027 & -1179 & -028 \\
\hline GEO & -7731 & -013 & -8051 & -024 & -7966 & -025 \\
\hline MAR & 0507 & 006 & 0609 & 007 & 0761 & 008 \\
\hline SAL & -3001 & -053 & -2717 & -047 & -2455 & -042 \\
\hline FOR & -5020 & -108 & -5249 & -110 & -5074 & -108 \\
\hline ALI & -1670 & -074 & -1775 & -079 & -1701 & -075 \\
\hline TIC & 6959 & 319 & 6744 & 334 & 6856 & 339 \\
\hline Constant & 12914 & 611 & 12934 & 637 & 12904 & 647 \\
\hline$\rho \sigma_{F}$ & -9755 & $2298^{b}$ & -9704 & $242^{b}$ & -9729 & $246^{b}$ \\
\hline
\end{tabular}

${ }^{\mathrm{a}}$ The statistics are robust to the presence of heterocedasticity (White, 1980)

${ }^{\mathrm{b}}$ The nullity contrast of $\rho \sigma_{F}$ uses a statistic $\chi^{2}$ with one degree of freedom

corresponding parameter is equal to one). This behaviour is apparently reasonable to the extent that the acquisition of equipment for the PRCs allows them to increase their infrastructure, which will in turn improve their future capacity to carry out research in collaboration with other firms.

In synthesis, the public agency finances approximately $100 \%$ of the acquisition of equipment for the PRCs. However, it is somewhat stricter when it comes to contributing funds destined towards the acquisition of fixed assets for the firm, especially if they are not directly related to research activities. The financed part of the rest of the costs is midway between the two.

In Table 7 it can be seen that the coefficients which accompany the variables that reflect the costs of those projects not destined to investment in the firm (BLABO, BMATE, BOTHER) and the PRC 
(CLABO, CMATE, COTHER) are quite similar. In the second specification of Table 7, it has been imposed that the parameters referring to these costs carried out in firm and PRC should be equal (four restrictions) and, consequently, these variables have been replaced by BNOTI and CNOTI. The results are qualitatively equal to those commented on in the first specification, and it is impossible to reject the hypothesis that firms and PRCs receive the same financing for the spending other than on investment, independently of whether they are to be destined to cover labour, materials or other expenses.

Again, the similarity between the coefficients of the variable costs of the firm and of the PRC (BNOTI and CNOTI) has led to the contemplation of the hypothesis that these costs are financed in the same way independently of whether they are carried out by the firm or by the PRCs. In the third specification of Table 7, BNOTI and CNOTI have been joined to make a single variable which comprehends all the project costs not destined to investment (NOINV). This restriction is statistically acceptable, obtaining results that do not alter significantly any of the other coefficients.

The rest of the variables has a similar incidence to any of the three specifications of the following model.

- The contribution tends to grow with the foreseen length of the project at a rhythm of 160,000 Pesetas $^{12}$ for each month.

- The effect of the variable COLAB is negative, indicating that the projects where there are the highest degrees of collaboration tend to receive less financing. ${ }^{13}$ This result appears to contradict the objective of integration into the system of science and technology characteristic of the concerted projects, since it implies a worse treatment for those projects that enjoy highest levels of PRC collaboration. An alternative explanation, which indicates a

\footnotetext{
${ }^{12}$ During the period 1988-1991 the average exchange rate was 110 Pesetas/Dolar

${ }^{13}$ The factor which is not taken into account is whether carrying out the research in PRCs is cheaper than doing so in the firms, that is, whether the action in itself of collaborating with researchers from the public sector implies a grant for the firm Of this is so, the requirement that PRCs participate in the project could be serving to make firm see the advantages in establishing links with universities or public research organisms
}

more favourable behaviour towards the projects developed with closest collaboration, consists of assuming that access to concerted projects has been made easier for those firms which, having lesser qualities for the development of precompetitive research, have presented proposals in which they assert their claim to collaboration from a PRC. In this way, the lesser financing of these projects would suggest that the approval of a proposal has been balanced with a slightly lower financing of the project.

In support of this second interpretation is the fact that the variable COLAB is negatively correlated to the residuals of the participation equation; that is to say, the lower the estimation of $I^{*}$, the higher the degree of collaboration from PRCs the approved projects tend to have. At any rate, this is a tentative result since the degree of collaboration from PRCs in the proposals which were rejected is unknown and, therefore, it is not possible to determine whether or not it has been a relevant factor for the approval of projects in firm with lesser qualities for the development of precompetitive research.

- The parameter which accompanies the other public financing variable (OTRPUB) indicates that the funds contributed by the National Plan are reduced when another public institution co-finances the project. However, the substitution is only partial, since for every additional Peseta of financing coming from the public sector, the National Plan only reduces its contribution by 0.33 Pesetas. In this way, even after taking into account the rest of the privileged loans and grants which the public sector awards to the firm, the parameter being considerably less than the unit, the firms are motivated to seek this co-financing.

- The public performance presents significant differences between 1988 and the rest of the period in question. The year 1988 was special in the financing of the concerted projects since, on average, the projects received an additional 7.2 million Pesetas. This fact can be explained since, being the first year of the concerted projects operation, relatively few were approved, thus allowing a more favourable treatment to be offered to them.

- Regarding the National Programmes, the technologies which on average receive most financing in relation to the New Materials programme, whose dummy variable has been excluded, are those of the 
National Programmes for Information Technology and Telecommunications, Microelectronics and Space Research. On the contrary, the projects integrated in Biotechnology, Agricultural research, Pharmaceutical research and development and Forest systems and resources tend to receive lower levels of funding. The rest of the programmes tend to receive a similar treatment to that of New Materials.

- The characteristics of the firm summarised by the five factors are significant except for SIZE, which measures the size of the firm. This means that the attributes of the firms which explain why they have or have not developed a concerted project (ORRD, RDCA, OTHER, PROXI) are taken into consideration when determining the financing awarded. The fact that the signs of all of these variables are contrary to those of the selection equation seems to indicate that the characteristics of the firms which explain why a firm has a concerted project have a negative influence in the amount received. In other words, the most R\&D activityorientated firm, those with most capacity to carry them out, as well as those which are most interested in the concerted projects, are more likely to obtain this funding, but the amount of the loan tends to be lower.

- Following the results from the estimation, the contrast of the selectivity bias carried out (Dhrymes, 1986, pp. 1625-1626), always rejects the hypothesis that $\rho \sigma_{F}$ is zero, indicating that it is necessary to consider the model with self-selection. In this way, the joint estimation of both equations is necessary to obtain consistent estimations of the importance of the characteristics of the chosen projects to determine the amount of the financing to be provided.

The negative sign of $\rho \sigma_{F}$ suggests the presence of unmeasured characteristics which act in an inverse way on the equations of participation and financing, which implies that among firms and projects with identical measured attributes, those firms with greater possibilities of having a project tend to receive smaller amounts of aid.

The results of the estimation of model (2) show that the observed characteristics of the firm (ORRD, RDCA, OTHER and PROXI) as well as the unobserved factors which positively affect participation in concerted projects imply that the firms with greater possibilities of applying for and obtaining a project are those which receive smaller loans. Although the model does not allow us to differentiate whether they are the most prone to applying for them or those for which the granting of a project is easiest, in both cases the public performance seems adequate. Thus, to the extent that these variables or the unobservable factors reflect the ease with which a firm has its proposal approved, the fact that the financing is lower may be reasonable if it is due to the fact that the public agency reduces aid to those firm with sufficient research capacity and which do not need loans in order to carry out more R\&D. On the other hand, to the extent that these variables synthesise the propensity of firms to present their applications for concerted projects, the lower financing is justified since it is no longer necessary to offer incentives in order that they participate.

At any rate, there is still a further possibility to explain the effect of unobserved characteristics, which is analogous to that provided by the negative sign of the COLAB variable. It may be that the public agency accedes to financing firms which present projects whose approval is not clearly justified according to their observed characteristics, but that in return it awards them a slightly lower level of financing than that which would correspond to them in accordance with the budget of the project and the rest of characteristics.

It is not possible to assure which of the above explanations is the most fitting. They may well all be valid for some groups of projects. In any case, they all respond to reasonable behaviour on the part of the public agency.

Finally, it is worth pointing out that, in the three specifications described, the hypothesis of joint nullity of all parameters is clearly rejected and, if the fit goodness of the model is measured by the value $R^{2}$ of the financing equation ${ }^{14}$, it is over 0.85 . Moreover, since the estimations obtained by maximum likelihood are very sensitive to the deviations of error distribution with respect to the normal; the normality contrast proposed by Pagan and Vella

\footnotetext{
${ }^{14}$ The $R^{2}$ has been calculated through the residuals of the financing equation of the model estimated by maximum likelihood
} 
(1989) for models with self-selection ${ }^{15}$ has been applied. In none of the three specifications the normality hypothesis is rejected, since the value of the statistic (which follows a distribution $\chi^{2}$ with three degrees of freedom) is $2.38,2.3$, and 2.2 , respectively.

\subsection{Determinants of financing of the national $R \& D$ plan}

To have an idea of the incidence of each variable in the amount of the loan granted, the estimated financing of the representative project has been calculated, whose variables take the average value of the approved projects. Taking into account the existence of selectivity bias, to estimate the financing awarded to the said project, expression (3) must be used, in which the parameters used are those estimated in the second specification of Table 7 (denoted by a circumflex). The last summing of this expression reflects the effect of the selectivity bias on the financing awarded to a project presented by a firm with $x_{I}$ characteristics, the expression $\lambda\left(x_{I} \beta_{I}\right)$ being the inverse Mill's ratio.

$$
(\hat{F} / I=1)=x_{F} \hat{\beta}_{F}+z_{F} \hat{\gamma}_{F}+w_{F} \hat{\theta}_{F}+\hat{\rho} \hat{\sigma}_{F} \lambda\left(x_{I} \hat{\beta}_{I}\right)
$$

The project with average characteristics has a probability of being converted into a concerted project of 0.60 and its estimated financing is of 53.3 million Pesetas, as contrasted with the real 53.1 million. Since the representative project has a budget of 120.5 million Pesetas, the National Plan finances $44.2 \%$ of the total budget, whereas the model predicts $44 \%$.

Table 8 reflects the effect which each one of the variables has on the determination of the amount of the loan awarded to the average project. Considering only the breakdown of the project budget, an approximation is obtained which is slightly higher than the financing awarded (54.6 million Pesetas), with the rest of variables supposing an effect of only -1.3 million Pesetas.

\footnotetext{
${ }^{15}$ A brief description of this test can be found in Maddala (1993, p 204)
}

Table 8

Contribution of the variables to the financing of the National Plan (Project with average characteristics)

\begin{tabular}{lc}
\hline Variable & Total effect $^{\mathrm{a}}$ \\
\hline BILAB & 11867 \\
BIFA & 1042 \\
BNOTI & 32045 \\
CEQUI & 1669 \\
CNOTI & 7976 \\
DU & 4496 \\
CON1 & 1299 \\
OTRPUB & -5681 \\
ORRD & -3918 \\
RDCA & -1703 \\
OTHER & -1430 \\
PROXI & -1333 \\
COLAB & 0000 \\
Type of project and constant & 13232 \\
Selectivity bias & -6235 \\
\hline
\end{tabular}

${ }^{\mathrm{a}}$ In millions of Pesetas During the period 1988-1991 the average exchange rate was 110 Pesetas/Dolar

This, however, must not be interpreted as meaning that the rest of variables do not have incidence in the financing received. What happens is that they compensate each other. Thus, the constant plus the effect of the dummy variables which include the belonging of the projects to the different National Programmes amounts to 13.2 million and if it is added that the average project receives 4.5 million because of its duration ( 28 months) and that the greater financing of the year 1988 contributes 2.3 million, 19 million is added to the loan. However, the other variables reduce the financing by 14 million and the selectivity bias by 6.3 million. Going a little further into detail, the limited impact (almost zero in the average project) of the COLAB variable becomes clear. On the other hand, the variables of the firm as a whole imply a reduction of 8.3 million.

The results which are obtained for the project with average characteristics are not a special case, since they are demonstrated quite generally, even if the effect of some of the variables, such as COLAB, may in some cases be more important. In the same way, the selectivity bias grows when we consider projects whose approval is not easily explained based on the characteristics observed in the firm which develops it. 
Public action according to the firm's staff

\begin{tabular}{|c|c|c|c|c|c|}
\hline Staff (no of people) & Up to 24 & 25 up to 99 & 100 to 249 & 250 to 999 & 1000 or more \\
\hline Number of projects & 56 & 85 & 78 & 78 & 80 \\
\hline Budget $^{\mathrm{a}}$ & 609 & 1020 & 1458 & 1480 & 1303 \\
\hline National Plan funding ${ }^{\mathrm{a}}$ & 290 & 456 & 646 & 632 & 564 \\
\hline Percentage of funding & 476 & 448 & 443 & 427 & 433 \\
\hline Preference $^{\mathrm{a}}$ & 168 & 049 & 232 & -201 & -201 \\
\hline Preference/Financing from Plan & $58 \%$ & $11 \%$ & $36 \%$ & $-32 \%$ & $-36 \%$ \\
\hline Probability of having project & 057 & 048 & 046 & 067 & 078 \\
\hline
\end{tabular}

${ }^{\text {a }}$ Monetary figures are expressed in millions of pesetas and correspond to the average of each group

\subsection{Financing of the national $R \& D$ plan and firm's characteristics}

An aspect worth studying is the influence of the firm's characteristics on the treatment of the projects by the public agency. The use of the indicators (SIZE, ORRD, RDCA, OTHER, PROXI) may not be altogether clear. It therefore seems appropriate to end this work by discussing the importance of the size of the firm which carries out the project (through its staff) and of its research capacity (personnel devoted to $R \& D$ activities) in the obtaining of concerted projects and the treatment of the projects undertaken by them.

In Tables 9 and 10 information is provided on the concerted projects, classifying them respectively according to staff numbers and the number of personnel devoted to $R \& D$ activities in the firm carrying out the project. The variables considered make reference to the representative project for each group, that is the project with average characteristics. These are the average budget for the projects, average financ- ing awarded by the National Plan and the percentage of the budget which is funded. The above variable is not appropriate to discuss the degree to which the public agency has prioritised the projects according to the firms' characteristics. The reason for this is that, since public financing largely depends on the characteristics of the project, the variability in the percentage financed may be justified by the differences between projects more than by the difference in treatment towards firms. In that sense, the variables of preference and preference in relation to financing awarded by the National Plan provide information on the way in which prioritisation has taken place according to the firm's characteristics. Finally, the probability that the representative firms of each group will participate in concerted projects is indicated.

The preference variable makes use of the estimated model to obtain a clearer vision of the influence of the firms' characteristics on the treatment of the project by the public agency. To this end, the financing which would correspond to each group's

Table 10

Public action according to the firm's R\&D personnel

\begin{tabular}{lllccc}
\hline R\&D personnel (no of people) & Up to 4 & 5 to 9 & 10 to 24 & 25 to 49 & More than 49 \\
\hline Number of projects $_{\text {Budget }^{\mathrm{a}}}$ & 88 & 50 & 83 & 68 & 88 \\
National Plan funding $^{\text {a }}$ & 660 & 9191 & 1244 & 1361 & 1756 \\
Percentage of funding $_{\text {Preference }}^{\mathrm{a}}$ & 298 & 423 & 562 & 597 & 744 \\
Preference/Financing from Plan $_{\text {Probability of having project }}^{4513}$ & 4608 & 4515 & 4382 & 4236 \\
& 428 & 099 & 015 & 057 & -243 \\
\end{tabular}

${ }^{\mathrm{a}}$ Monetary figures are expressed in millions of pesetas and correspond to the average of each group 
representative project has been foreseen according to all of its characteristics (according to expression (3)), but without considering the indicators relating to the firm carrying out the project (ORRD, RDCA, OTHER y PROXY), the unobservable factors (selectivity bias) nor the degree of cooperation with PRC (COLAB). ${ }^{16}$ The difference between the funding awarded by the public agency to the representative project and the amount estimated by this procedure is a measure of the effect of the characteristics of the representative firm on the amount of the loan. The preference variable measures the divergence of the above measurement between the representative project and the average project out of the 377 analysed. In this way, the preference variable covers the additional funding which each group's representative project receives as a result of the effect of the firm which carries it out.

The number of projects awarded is distributed in a fairly uniform way between all the categories of firm size and R\&D department, although, as one would expect, the budget of the concerted projects tends to increase according to the size and research capacity of the firm. Anyway, it is the larger firms (250 or more employees) which present greater probabilities of receiving the award of a concerted project, followed by those with fewer than 25 employees. Table 10 shows that the size of the $\mathrm{R} \& \mathrm{D}$ department is associated with a greater likelihood of undertaking concerted projects, but it is striking that firms with between five and nine employees in their R\&D department tend to participate less than those with fewer than five.

In accordance with the preference and preference/funding variables, it can be said that the differences in funding awarded attributable to the peculiarities of firms are small. The most favoured projects have been those carried out by firms with fewer than 25 workers with almost $6 \%$ of additional funding over what should have corresponded to them according to the characteristics of the project. On the other hand, the larger firms (250 or more employees) have seen a reduction in their funding of a little over $3 \%$.

\footnotetext{
${ }^{16}$ The effect of the COLAB variable has been considered because it may be related with characteristics of the firm which explain the degree to which PRC collaboration is necessary
}

On the question of R\&D personnel, those firms with large $\mathrm{R} \& \mathrm{D}$ departments (which have developed the largest-scale projects) have received less than average funding. The rest of the projects are above the average, especially those carried out by firms with fewer than five people devoted to R\&D activities.

\section{Conclusions}

The aim of this work is to analyse the action of the administration when funding precompetitive projects carried out by firms with the cooperation of PRCs. One of the results obtained is that the project budget and the destination of this budget are the most important factors to explain the financing awarded to a project. The maximum financing is provided when equipment is acquired for the participant PRCs, which is reasonable if it is taken into account that they could be re-used later by the PRCs for their own research. On the other hand, it is much less when it comes to incorporating fixed assets for the firm. The rest of the expenses which the projects generate are treated in an intermediate way.

In fact, the results obtained seem to indicate that the public performance has consisted of applying quite general criteria to all the projects which were acepted, without significantly favouring those that, in principle, because of their characteristics, were closer to the objectives of fomenting R\&D activities and encouraging cooperation between PRCs and firms. Even so, it seems to be detected that public action tends to finance a little more generously those firms with less tendency to participate in concerted projects. This behaviour means that the larger firms, with large $\mathrm{R} \& \mathrm{D}$ departments, receive less funding than the rest. On the other hand, very small firms, in which a considerable proportion of their staff are devoted to R\&D activities, are most favoured.

The question which immediately arises is whether or not the public agency has adequately chosen which groups to favour. To answer this question in any conclusive way, it would be necessary to study whether or not more support has been given to those firms which require more public incentives to collaborate with PRCs or to carry out precompetitive re- 
search projects. This task lies outside the limits set by the aims of this work and, indeed, it is not possible to carry out using the administrative information available. Even so, the way in which the public agency has acted may be justified by the following arguments. To favour small firms would seem appropriate inasmuch as for the smaller firms, the concerted project may serve as a first contact with the PRCs which might prove fruitful later in the establishment of lasting links, both formal and informal, and it must not be forgotten that the small firms are the ones which most benefit from this type of relations (Link and Rees, 1990). Moreover, smaller firms are those which face greater difficulties in finding external funding, which makes it highly likely that the loans awarded serve to make it possible to initiate other research projects. On the other hand, larger firms have much easier access to external funding, and therefore possibly do not have too many economic problems when it comes to embarking on research projects. For this reason, it is not clear that the concerted projects are fundamental to generate more R\&D activity. Again, to determine the effect on collaboration with PRCs will require more detailed analysis, although given the results obtained by Link and Rees (1990) and Buesa and Molero (1992), firms with large R\&D departments normally collaborate more often with PRCs. In this sense, the collaboration established in the concerted projects is probably not new, but originates from already established links. In conclusion, if the above arguments are accepted, the action of the administration can be considered correct with respect to its orientation, but there may be a need to prioritise to a greater extent some categories of firms in relation to the rest.

\section{Acknowledgements}

We are grateful to Victor Cano, Praveen Kujal, Stan Metcalfe, Manuel Navarro, Maria del Pilar Osorno, Olga Rodriguez and three anonymous referees for useful comments and suggestions. We also wish to point out that the information contained in this paper had been obtained thanks to the collaboration of the Centre for Industrial Technological Development (CDTI) and the Interministerial Commis- sion for Science and Technology (CICYT). This work has received financing form the National R \& D Plan (Projects SEC93-833-CO2 and SEC97-1331).

\section{References}

Acosta, J., Modrego, A., 1997. La colaboración entre empresas y centros públicos de investigación españoles a través de los proyectos concertados del Plan Nacional de I+D. Memorias del VII Seminario Latinoamericano de Gestión Tecnológica 271-288.

Acosta, J., Modrego, A., 1998. La actuación pública en los proyectos concertados del Plan Nacional de I + D, Documento de Trabajo de la Facultad de Ciencias Económicas y Empresariales, $n^{\circ}$ 97/98-8. Universidad de La Laguna.

Amemiya, T., 1984. Tobit models: a survey. Journal of Econometrics 24, 3-61.

Arnés, H., 1990. Participación española en los programas de I+D de la CE. Economía Industrial 275, 69-82.

Arora, A., Gambardella, A., 1991. Evaluating technological information and utilizing it, Working Paper $n^{\circ}$ 91-40. Carnegie Mellon University.

Arora, A., David, P.A., Gambardella, A., 1998. Reputation and competence in publicly funded science: estimating the effects on research group productivity. Annales d'Economie et de Statistique 49-50, 163-198.

Azároff, L.V., 1982. Industry-university colaboration: how to make it work. Research Management 3, 31-34.

Bailetti, A.J., Callahan, J.R., 1992. Assessing the impact of university interactions on an $R \& D$ organization. R\&D Management 22, 145-156.

Bonacorsi, A., Piccaluga, A., 1994. A theoretical framework for the evaluation of university-industry relationships. Research Management 24, 229-247.

Buesa, M., Molero, J., 1992. Patrones del cambio tecnológico y política industrial, Un estudio de las empresas innovadoras madrileñas. Civitas-IMADE, Madrid.

Busom, I., 1991. Innovación tecnológica e intervención pública: panorama y evidencia empírica, Tesis doctoral no publicada. Universidad Autónoma de Barcelona.

Cohen, W.M., Levinthal, D.A., 1989. Innovation and learning: the two faces of R\&D. Economic Journal 99, 569-596.

Cohen, W.M., Levinthal, D.A., 1994. Fortune favors the prepared firm. Management Science 40, 227-251.

Dean, C.W., 1981. A study of university/small firm interaction for technology transfer. Technovation 1, 109-123.

Dhrymes, P.J., 1986. Limited Dependent Variables, in Griliches, Z, M.D. Intriligator (Editors), Handbook of econometrics vol. 3 (North-Holland, Amsterdam) pp. 1567-1631.

Faulkner, W., Senker, J., 1994. Making sense of diversity: public-private sector research linkage in three technologies. Research Policy 23, 673-695.

Fontela, E.;, Pulido, A.; Sanchez, M.P., Vicens, J., 1992. Evaluación de la actuación del CDTI en apoyo a la I+D. Centro para el Desarrollo Tecnológico Industrial, Madrid. 
Fowler, D.R., 1984. University-industry research relationships. Research Management 1, 35-41.

Gibbons, M., Johnston, R., 1974. The roles of science in technological innovation. Research Policy 3, 220-242.

González Ayuso, J., Comesaña, J., Criado, E., Aragón, J., Durán, A., 1993. Actividades de I + D y transferencia de tecnología en la empresa española. Economía Industrial 289, 103-134.

Greene, W.H., 1991. Econometric Analysis. MacMillan Publishing, New York.

Ham, R.M., Mowery, D.C., 1998. Improving the effectiveness of public-private R\&D collaboration: case studies at a US weapons laboratory. Research Policy 26, 661-675.

Höglund, L., Persson, O., 1987. Communication within a national R\&D-system: A study of iron and steel in Sweeden. Research Policy 16, 29-37.

Lee, Y.S., 1996. Technology transfer and the research university: a search for the boundaries of university-industry collaboration. Research Policy 25, 843-863.

Link, A.N., Rees, J., 1990. Firm size, university based research, and the returns to R\&D. Small Firm Economics 2, 25-31.

Maddala, G.S., 1983. Limited dependent and qualitative variables in econometrics. Cambridge Univ. Press, Cambridge.

Maddala, G.S., 1986. Disequilibrium, self-selection, and switching models, in Griliches, Z., M.D. Intriligator (Editors), Handbook of econometrics, vol. 3, North-Holland, Amsterdam, pp. 16331688.

Maddala, G.S., 1993. Contrastes de especificación en modelos de variable dependiente limitada. Cuadernos Económicos de I.C.E. $n^{\circ} 55,185-223$.

Manski, C., Wise, D., 1983. College Choice in America. Harvard Univ. Press, Cambridge, Mass.
Modrego, A. (director), 1995. Evaluación de los proyectos concertados del Plan Nacional de I + D, Report to Centre for Industrial Technological Development (CDTI).

Molero, J., Buesa, M. (directors), 1997. La innovación tecnológica en la empresa española. Resultados de la encuesta IAIF-CDTI (1995), Documento de trabajo $\mathrm{n}^{\circ}$ 5, Instituto de Análisis Industrial y Financiero.

Mowery, D.C., 1983. The relationship between intrafirm and contractual forms of industrial research in American manufacturing. Explorations in Economic History 20, 351-374.

Mowery, D.C., Rosenberg, N., 1989. Technology and the pursuit of economic growth. Cambridge Univ. Press, Cambridge.

Pagan, A.R., Vella, F., 1989. Diagnostic tests for models based on unit record data: a survey. Journal of Applied Econometrics 4, S29-S59.

Senker, J., Faulkner, W., 1992. Industrial use of public sector research in advanced technologies: a comparison of biotechnology and ceramics. R\&D Management 22, 157-175.

Sheen, M.R., 1992. Barriers to scientific and technological knowledge acquisition in industrial R\&D. R\&D Management 22, $135-143$.

Van Dierdonk, R.V., Debackere, K., Engelen, B., 1990. University-industry relationships: How does the Belgian academic community feel about it? Research Policy 19, 551-566.

Veugelers, R., 1997. Internal R\&D expenditures and external technology sourcing. Research Policy 26, 303-315.

White, H., 1980. A heteroscedasticity-consistent covariance matrix estimator and a direct test for heteroscedasticity. Econometrica 48, 817-838. 